\title{
Las sociedades y la elaboración de calendarios
}

\author{
Ligia Carvajal M.*
}

Recibido: octubre 2010 • Aceptado: marzo 2011

\section{RESUMEN}

El presente artículo versa sobre el desarrollo de las sociedades y su necesidad de confeccionar calendarios como mediciones del tiempo; para ello, utilizaron la observación de los astros, fenómenos naturales, acontecimientos sociales relevantes, que dieron origen a festividades religiosas y seculares, las cuales por su importancia debían registrarse en el tiempo.

Palabras claves: Sociedad, gens, tribu, clan, sedentarismo, agricultura, astronomía, medición, calendario.

\begin{abstract}
The present article is about the development of the societies and the necessity of these to make calendars like measurements of the time, for which they used the observation of the stars, natural phenomena and excellent social events, that gave origin to religious and secular festivities and that by its importance it was necessary to register them in the time.
\end{abstract}

Key words: Society, gens, tribe, clan, sedentarism, agriculture, astronomy, measurement, calendar.

\section{Introducción}

En los tiempos primitivos, el ser humano dependía de la naturaleza que le rodeaba, vivía completamente agobiado por las dificultades de la existencia e incluso de la lucha contra la naturaleza. Por eso, tuvo que inventar sus propias herramientas materiales y espirituales, esenciales en la conformación de su visión de mundo.

Durante la etapa primitiva, el hombre mantuvo su existencia gracias a la recolección de los frutos que era una actividad suplementaria y a la caza, que requería

* Profesora de la Universidad de Costa Rica. Docente en Escuela de Estudios Generales. Historiadora. carvajalligia@hotmail.com 
esfuerzos continuos; no obstante su recompensa era incierta. Ambas labores se efectuaban colectivamente. Sin embargo, no se sabe cuando los miembros de las hordas de cazadores primitivos empezaron a reconocer grados de consanguinidad, así como otros aspectos de diferenciación social, como la jefatura y las clases. Se cree que las tribus se formaron como resultado de la conservación de un vínculo de parentesco en una población cada vez más numerosa que ocupaba territorios más vastos.

Al incrementarse la población, en la sociedad primitiva contemporánea aparecieron dos tipos de organización social: el clan, basado en el parentesco por línea femenina o materna y la gens, en la cual el parentesco se estableció por línea masculina o paterna. Ambas organizaciones protegían a sus miembros, los preparaban para la guerra, para compartir una vida en común, así como los diversos trabajos y sus beneficios. También fue importante la organización familiar: matriarcado y patriarcado. El primero fundamentado en la madre, en el hermano de la madre; el segundo en el padre; éste predominó cuando apareció la propiedad de ganados y de tierras.

Los cambios climáticos que acontecieron durante el retroceso de los glaciales, le permitieron al ser humano aprender sobre los procesos de desarrollo de las plantas y de los animales para contar con una fuente de abastecimiento de alimentos más segura. Por eso, introdujo progresos de reorganización casi por completo en la vida ordinaria de la sociedad.

“...Algunos indicios señalan el valle del Nilo como patria primitiva de la vida sedentaria y colectiva, fundada en el cultivo de la tierra. Ciertos hallazgos inducen también a pensar que apareció por primera vez en Arabia septentrional, Palestina o Siria, y otros se mueven a opinar que nació tal vez en las crestas calizas de la meseta de Armenia, de donde son oriundos varios animales y plantas aptos para el servicio del hombre..." (Turner, 1974:64).

El cultivo de la cebada, el mijo, algunas especies de trigo, así como el cuido de animales: el cerdo, la vaca, la cabra y la oveja muestran cambios en la sociedad primitiva que posiblemente influyeron en la fijación de fechas para la celebración de festividades. También, en los tiempos en que el ser humano se dedicaba a la caza de animales, a la recolección y aún no experimentaba la etapa sedentaria, tuvo conocimiento acerca de la migración de animales y del momento en que los árboles cambiaban su follaje y producían los frutos. La observación de estos hechos constituyeron las primeras bases de lo 
que posteriormente se denominarán calendarios.

\section{Sociedades antiguas}

En el contexto descrito anteriormente, la agricultura y el pastoreo fueron adquiriendo relevancia; las personas se interesaron por diversos tipos de labores productivas. Ambos trabajos dieron origen a la división social del trabajo en las distintas comunidades. La segregación de las tribus de pastores fue la primera experiencia de esta división.

Las labores agrícolas y ganaderas abrieron paso a otras actividades como la alfarería, la producción de tejidos manuales; luego, la fundición del cobre y del hierro hizo posible que las personas se dedicaran a diferentes oficios. Poco a poco, esa primera organización social se dividió en grandes familias patriarcales. Posteriormente, en el seno de la gran familia patriarcal, se constituyeron pequeños núcleos familiares aislados, que convirtieron los instrumentos de producción, los utensilios domésticos, el ganado en su propiedad privada. De ahí que los vínculos gentilicios fueran perdiendo fuerza, desarrollándose asi, la propiedad privada. También, con el debilitamiento de las gens, surgió la comunidad rural de vecinos, que no requería de lazos de parentescos. En esta nueva organización social, al principio, la tierra y otros recursos fueron comunales, pero posteriormente adquirieron carácter privado:

“...A menudo coexisten varios tipos de derechos de propiedad sobre las tierras. Unos terrenos pertenecen a la tribu, otros al clan y otros a los individuos. Entre los nómadas es común la propiedad familiar, administrada por el padre y sólo entre los aldeanos se encuentra en toda su plenitud el derecho a propiedad privada sobre los terrenos de labranza..." (Turner, 1974:87).

Los cambios constantes en la agricultura, la domesticación de animales, así como la especialización en la actividad productiva por parte de algunos grupos, fueron indispensables para la conformación de las aldeas agrícolas indiferenciadas y las hordas pastoriles nómadas.

Todos estos aspectos posibilitaron el surgimiento de las ciudades, de los Estados, así como la estratificación de las sociedades en clases sociales. De hecho, el invento de las técnicas de irrigación, los procedimientos para abonar el suelo, la aplicación del arado en las tareas de labranza de la tierra y el empleo de la rueda en el transporte complementada con la tracción animal, aseguraron aumentos en las cosechas. De ahí, que diversos pueblos pusieran en práctica estas 
invenciones y con el afán de aumentar su capacidad productiva crearon nuevas técnicas. Este despertar técnico favoreció el surgimiento de las primeras ciudades, así como otras necesidades que generaron nuevas técnicas apreciables en la fabricación de tejas, ladrillos, vidrios, en la metalurgia del cobre, del bronce y de los silos (Ribeiro, 1976).

Efectivamente, la aparición de la ciudad fue un paso importante en la evolución social del ser humano. Los primeros asentamientos urbanos surgieron donde las artes neolíticas avanzadas eran más productivas. Estos territorios contaban con recursos importantes: abundante agua para el regadío por gravedad, un clima agradable, facilidades de transporte, llanuras aluviales cercanas a ríos. Estas condiciones las presentaban el Valle de México, la Mesopotamia, el río Nilo, el Perú, el Mediterráneo Meridional, entre otras.

La historia señala que las primeras ciudades aparecieron en el 3.500 antes de Cristo en la Mesopotamia, en el Valle del río Tigris, el Éufrates, el Nilo y en el río Amarillo en China. La mayor parte de las ciudades surgieron en Sumeria: Kish, Eridu, Erich y Ur. Estos establecimientos presentaban tres elementos fundamentales que deben tener los asentamientos urbanos: uso de técnicas: piedra, hacha, plantas, arado; materias primas para elaboración de objetos, así como técnicas para la construcción de viviendas. Además, tendrían a su vez artesanos, funcionarios y comerciantes. Así, la aldea se convirtió en centro de intercambio, recopiladora o creadora de inventos, eje de diversas actividades.

Las ciudades fueron los espacios donde se concentraron los artesanos: alfareros, tejedores, vidrieros, metalúrgicos, entre otros. Los comerciantes se encargaron del intercambio de productos agrícolas y artesanales. A ellos, se unieron los sacerdotes, funcionarios y soldados que desempeñaban diferentes funciones. De hecho, la ciudad se puede considerar como una comunidad de considerable magnitud y elevada población que alberga cantidad de trabajadores especializados no agrícolas, grupos que se encargarán de la instrucción y del desarrollo de la escritura ideográfica, porque la mediación fundamental que privaba en ese momento, era la oralidad; no existían sistemas jurídicos complejos; no obstante, ya comenzaba a vislumbrarse un desarrollo de la ciencia de la numeración, así como la elaboración del calendario. Todos estos aspectos dieron origen a los Estados rurales artesanales.

“...las distintas necesidades materiales -alimento, vestido, alojamiento-dan origen a otros tantos 
oficios que se reparten entre individuos distintos. Conforme va creciendo la ciudad aparecen nuevas necesidades que provienen del progresivo refinamiento de la vida o de las relaciones con otras ciudades, dando origen a nuevas actividades $y$ funciones diferenciadas: la navegación, el comercio, etc.

La ambición o la necesidad de ampliar el propio territorio será causa de choques violentos con otras ciudades vecinas que se habrán ido formando de manera semejante. De aquí brota la necesidad de otra función especializada, que será la de guardianes, milicia permanente, que deberá dedicarse exclusivamente al oficio de la guerra para la defensa de la ciudad. La vida misma de la ciudad exige otra función importantísima que será la del gobierno, la cual deberá ejercerse por una minoría selecta, cuya misión consistirá en regular las relaciones entre los ciudadanos, y de éstos con la ciudad, asignando a cada miembro de ella la función que le corresponde dentro del conjunto social..." (Fraile, 1966:364).

En la ciudad, los sacerdotes fueron los antiguos "Chamanes" quienes se encargaron de cohesionar moralmente las diversas capas sociales; para ello, se fundamentaron en las viejas prácticas y costumbres religiosas, las cuales necesariamente tuvieron que rediseñarse para que cada sujeto, de acuerdo con sus características, encontrara sentido a su existencia, a pesar de las contradicciones presentes en su entorno. En ese quehacer, los sacerdotes se convirtieron en doctos capaces de explicar el destino humano, de orientar el trabajo, de determinar los períodos apropiados para las diferentes actividades agrícolas. Posteriormente, fueron capaces de codificar todo el saber tradicional y ajustarlo a las nuevas necesidades. Así, se organizaron cuerpos burocráticos y se institucionalizó en las iglesias la antigua religiosidad compartida. Es decir, la ciudad albergaba distintos modos de vida.

Como se puede observar, el ser humano ha evolucionado socioculturalmente cambiando modos de ser, de vivir y de pensar. Por eso, desarrolló una serie de inventos que han provocado revoluciones en diferentes áreas. Así, el proceso de adaptación y asociación fueron fundamentales para la institucionalización, la organización del trabajo y el ordenamiento de la convivencia social a través de instituciones políticas, religiosas, educativas, entre otras.

El desarrollo técnico continuó, las grandes obras de irrigación desencadenaron la revolución del regadío, así como la aparición de los imperios teocráticos de regadío. El progreso técnico también alcanzó la metalurgia y generó una revolución que se aprecia en algunas 
innovaciones en el hierro forjado, lo que facilitó el desarrollo de una agricultura más productiva en las áreas forestales, la fabricación de diversas herramientas de trabajo y, con éstas, el mejoramiento de los veleros. A estos avances, se le suma la acuñación de monedas, esenciales para el desarrollo del comercio externo; el alfabeto fonético, la notación decimal. Todo esto ayudó a la configuración de imperios mercantiles esclavistas.

En el área pastoril también ocurrieron cambios; gracias a los avances de la técnica del hierro fundido se pudo utilizar sillas, estribos, herraduras, arnés rígido, para aumentar la eficiencia de los animales de montura y de tracción. Este hecho permitió el expansionismo de algunos pueblos que atacaron áreas feudales de antiguas civilizaciones consolidándolas como imperios despóticos.

Así como las personas se organizaron en materia económica social, también en el campo ideológico se vislumbraron cambios. En el pensamiento aparecieron interrogantes sobre la concepción de lo humano, del entorno y de los fenómenos de la naturaleza. Estos aspectos originaron una serie de mitos explicativos de todas estas interrogantes, que denotan una relación entre un espíritu capaz de adoptar forma humana o animal. El mito también gira en torno a elementos de carácter humano; resalta la debilidad o la fortaleza humana, castigada o premiada por los espíritus. En el mundo mitológico, se combinan imágenes, efectos, narrativas. Por eso, el mito promueve los rituales o actos realizados por la colectividad, con el fin de agradar a los poderes superiores. En las culturas primitivas estas celebraciones se hacían en situaciones críticas del grupo. De ahí, que el mito se considere como una historia sagrada y hasta verdadera, porque se refiere siempre a realidades: "... el mito cosmogónico es "verdadero" porque la existencia del mundo está allí para probarlo, el mito de origen de la muerte es igualmente "verdadero", puesto que la mortalidad del hombre lo prueba, y así sucesivamente..." (Eliade, 1973:23).

La creación mitológica aumentó, porque cada individuo o grupo buscó sus propias respuestas, creó su concepción de mundo de acuerdo con sus interrogantes y actividades. Para los grupos pastoriles, la existencia de un dios celestial relacionado con la tempestad y con el sol fue fundamental en el desarrollo de sus labores; el hecho de poner en práctica el patriarcado, les permitió otorgarle a esa divinidad características masculinas de jefe, de padre violento y arbitrario, que efectivamente requería de sacrificios de animales para aplacar su ira y agradarlo. 
Los mitos relatan el origen del mundo, de los animales, de las plantas, del hombre, así como todos los acontecimientos primordiales de la sociedad; por este motivo, éstas en su afán de registrar estos fenómenos cíclicos en el paso del tiempo, inventaron los calendarios definidos como sistemas para dividir el tiempo en días, períodos lunares y repetición de estaciones del año.

\section{Sociedades modernas}

El ser humano, en su capacidad creadora, inventó la máquina de vapor, cuyo objetivo fundamental consistió en la conversión de energía calórica en mecánica, para generar energía más eficiente, sin tanta fuerza humana. Esta máquina se convirtió en el instrumento que posibilitó que la revolución industrial se gestara y desarrollara en Inglaterra, se extendiera a Francia, Alemania, Estados Unidos, Japón y finalmente al mundo entero. No existe duda de que esta invención técnica fue la más importante del siglo XVIII por el impacto económico, social, ambiental que produjo en Europa y en el resto del mundo.

\section{Organización de calendarios}

Es obvio que las invenciones continuas en materia técnica facilitaron nuevas actividades. La comercialización experimentó cambios importantes que la revolucionaron y permitieron la expansión de las primeras civilizaciones mundiales, imperios mercantiles con áreas de dominación conformadas principalmente como colonizaciones esclavistas. A este proceso se le adicionaron nuevos cambios técnicos que permitieron la configuración de las primeras formaciones capitalistas mercantiles en la era moderna.

A todas esas transformaciones se deben sumar otros elementos esenciales en la formación de un sistema ideológico que comprende las distintas formas de pensamiento, la creación de técnicas productivas, las diversas formas de comunicación, las creencias, órdenes de valores que permiten explicar el modo de vida, así como la manera de conducirse.

En ese sentido, la observación y el estudio del cosmos fue un factor determinante en la elaboración de los calendarios, indispensables para programar las actividades agrícolas y recordar fechas importantes que la comunidad celebraba por medio de actividades religiosas, de prácticas culturales vinculadas con los fenómenos naturales, de festividades, como por ejemplo, las relacionadas con las cosechas, las cuales, se repetían periódicamente; sin embargo, al principio sólo se guardaron celosamente en la memoria.

La elaboración de los calendarios se remonta hasta la 
antigüedad, se fundamenta en la posición relativa de los astros respecto de la Tierra. En un principio no se consideraba el traslado anual de nuestro planeta por la elíptica y su posición respecto del Sol, porque este aspecto era desconocido por los astrónomos de la época. Pero, la posición de las estrellas en el mismo lugar de la esfera celeste se repetía año a año; este aspecto periódico, así como otros del comportamiento de la naturaleza que se habían observado con bastante precisión, como el cambio de las estaciones, las fases lunares, sirvieron de sustento para las propuestas de los calendarios, partiendo de una concepción estática de la Tierra.

Desde sus inicios, la humanidad ha observado con admiración los cambios que presenta la luna; este acontecimiento se repite cada veintinueve días y medio, por medio de cuatro fases, a saber: luna llena, el cuarto menguante, luna nueva, cuarto creciente, repitiéndose cada una de estas fases cada 7,375 días. Esta es la razón por lo que la semana se consignó en siete días, lapso que corresponde aproximadamente a cada fase de la luna y la de cada mes, período en que cada fase lunar se repite.

Los primeros calendarios se basaron en las veces que aparecen las lunas nuevas en un lapso donde los acontecimientos celestiales se repiten. De hecho, las lunas nuevas se repiten 12,37 veces durante el período que requieren las constelaciones zodiacales para ocupar periódicamente la misma posición en el firmamento, después de un recorrido circular por la esfera celeste. Por comodidad, los antiguos redondearon ese número a doce espacios temporales, porque era más sencillo trabajar sin decimales. De esta manera se pone en “...correspondencia los meses del año con aquellas constelaciones zodiacales sobre las cuales se proyectaba el Sol observado desde la Tierra..." (Bia1ko, 1985:31).

La historia del calendario muestra los intentos de los sacerdotes y astrónomos por establecer un adecuado sistema de medición del tiempo. En sus orígenes los primeros calendarios fueron imprecisos, se requería de constantes readecuaciones para que fueran funcionales. Los sumerios, por ejemplo, cultura que se remonta a 3000 años antes de Cristo, tenían sacerdotes que registraban los datos astronómicos en tablas de arcilla que servían de base para la preparación de los calendarios. $\mathrm{Su}$ calendario consistía en doce meses de treinta días, por lo que consideraban que un año contaba con trescientos sesenta días, por lo tanto, se veían obligados a reformarlo constantemente; su división era inexacta, porque se basaban en los ciclos lunares y para que 
concordara con el año solar, a veces le agregaban un mes (Mc Nall, 1970:85).

Estos registros temporales se asociaban al principio con la memoria; pero ésta no fue suficiente, sino que era necesario dejar una huella. Por eso, se recurrió a diversos materiales como la arcilla, la madera, la piedra. En esta tarea, el ser humano tuvo que tomar en consideración los fenómenos de la naturaleza que lo afectaban directamente. De hecho, durante el período nómada posiblemente la medida del tiempo consistió en determinar este de acuerdo con la luz solar; así se estableció una medición que permitiera fijar el día, la noche, es decir, el tiempo solar. Este hecho, aunado al cambio de las estaciones: primavera, verano, otoño e invierno, facilitó la medición anual. Todo este conocimiento sirvió para que las personas solventaran sus necesidades básicas, como se puede observar en el mundo del pastoreo, donde la primavera es una época trascendental, porque la abundancia de pastos facilita el celo de las hembras para su posterior gestación, o bien, en el caso del ganado vacuno que las crías nacen a principio del invierno. Se supone que ambos hechos son motivo de festejos. El ser humano, conocedor de su entorno, también observó el cielo, pudo detectar que algunas estrellas tienen más luz que otras, que su distribución es diferente. El transcurrir del tiempo le permitió comprobar que algunos días presentaban mayor duración de la luz solar que otros, o en sentido contrario, noches más cortas y días más largos. Los acontecimientos periódicos más importantes ocurren durante el día, la noche, así como en el cambio de las estaciones del año.

La vida cotidiana se halla estrechamente articulada con el Sol, que es el astro más grande del sistema solar, considerado por los cosmólogos como una estrella mediana dentro del conjunto de estrellas del universo.

Una vez que se dio la sedentarización, y con ello la agricultura, la medición del tiempo, las estaciones, la cantidad de lluvia, el sol y el viento, desarrollaron en el ser humano la necesidad de mayor conocimiento y de una mejor calendarización. Las cosechas, dependían en parte de la experiencia adquirida a través del tiempo, del sol y de la lluvia. Todos estos elementos posibilitaron la observación de los cultivos para saber cuanto duraba una planta en germinar, crecer y dar fruto. Todo este proceso debía coincidir con los días, con los cambios de estaciones.

Con la sedentarización, también se inició un proceso de domesticación de animales, los cuales debían ser apacentados; normalmente, algunos de éstos se recluían en corrales durante la noche, otros 
debían ser cuidados por personas, e incluso existieron hordas pastoriles nómadas, como los primeros grupos de criadores de ganado mayor de Asia, de Siberia, de Mongolia, del norte de África. Es posible, que durante la labor del cuido del ganado, los pastores observaran el cielo nocturno. Conforme pasó el tiempo, detectaron cambios en la conformación de esa cúpula nocturna y comenzaron a vincular ese conocimiento con el tiempo.

Todo lo anterior coincide con lo que se conoce por algunos autores como el primer proceso civilizatorio, que dio inicio con la revolución agrícola cerca de diez mil años entre pueblos como el mesopotámico, el egipcio, y que luego se difundió en India (6000 antes de Cristo), China (5000 antes de Cristo), Europa (4500 antes de Cristo). Después llegó al África Tropical (3000 antes de Cristo), a América (2500 antes de Cristo) (Ribeiro, 1976, 49).

La etapa de sedentarización, así como el trabajo de pastoreo, fueron fundamentales para el conocimiento del tiempo y su medición, como se anotó anteriormente, porque el hombre vinculará los astros con su quehacer, en virtud de que la astronomía será la ciencia que le permitiría un mejor control de su entorno al humano; esto le ayudará a solventar sus necesidades básicas mediante el trabajo en el día, durante el año. Entonces, no es de extrañar que en las diversas culturas pronto los astros adquirieran carácter de dioses. En Egipto apareció el Dios Ra; Mercurio y Marte en Europa mediterránea.

\section{Culturas asiáticas}

En el ámbito de esa vinculación astros con el quehacer humano y divinidades, las culturas asiáticas también destacan. Tanto los sumerios como los babilónicos contaban con millares de divinidades, entre los que sobresalen seis grandes dioses: Anú, que era el Dios del cielo; Enlil Dios del aire, del viento; Ea o EnKi, Dios de la tierra, de las aguas subterráneas frescas; Sin, el dios de la luna; Nintud o diosa de la fecundidad y Utu que era el Dios del Sol. Además, estas culturas dividieron a los dioses en dos grandes grupos: los Igigi, o dioses del mundo, del cielo y los Anunnanki o dioses del mundo inferior que también se conoce como el sheol (Tunner, 1974).

Pero, estas culturas no sólo estructuraron su mundo ideológico a partir de estas divinidades, sino que iniciaron el proceso de la medición del tiempo, que según algunos autores, constituye el primer momento del desarrollo científico. Es decir, sumerios y babilonios se les conoce en la historia como los fundadores de la ciencia. Ellos construyeron sistemas para medir el tiempo, la 
distancia, el espacio y las cantidades; aunque otras culturas también lo hicieron; los textos coinciden que estas mediciones no fueron tan exactas como las de ellos.

Los babilonios, basados en las observaciones astronómicas, dividieron el día en 24 horas (dos horas para cada constelación del Zodíaco), la división de la circunferencia en 360 grados (el sol pasa por la elíptica $1^{\circ}$ al día, aproximadamente, la división de la hora en $60 \mathrm{mi}$ nutos, del minuto en 60 segundos, así como la división del grado en minutos y segundos angulares (Bialko, 1985).

Para los babilónicos, el año tenía 360 días; éste se obtuvo a partir del movimiento solar, los meses se fundamentaban en los movimientos lunares. El movimiento lunar y solar no coincidían, por ello, los sacerdotes sobreañadían días a su calendario, según su criterio, para hacerlo más exacto. Así, crearon la semana compuesta por siete días que se identificó con los siete cuerpos celestes movibles que observaban. El séptimo día se consideró un día de descanso, criterio que asumieron las religiones asiáticas y las diferentes sociedades lo fueron incorporando a su vida cotidiana. El cálculo de los minutos, los segundos, cuya cifra es el número sesenta, posiblemente se hizo con base en el sistema de numeración sumerio que establecía como base contable el sesenta. Además, el día babilónico tenía una duración de doce horas; no obstante, no fue hasta que apareció el reloj mecánico, cuando esta medición se generalizó en todas las culturas.

La diferencia entre el movimiento solar y lunar planteado por los babilónicos, es comprensible, porque el año solar se compone por 365 días, 5 h, 48 m, y 45,5 s. En cambio, la medición lunar dio lugar a un año de 354 días; es decir, 11, días más cortos que un año solar.

Los sumerios, así como los babilónicos observaron la aparición y desaparición de los cuerpos celestes en el firmamento; esto permitió que sus cálculos fueran tan exactos que todavía persisten para determinar órdenes cronológicos de acontecimientos. Esos movimientos celestes también los asociaron con la voluntad de los dioses, por ello, se plantearon la causalidad universal de todos los acontecimientos.

También en las sociedades antiguas existió la medida de un mes a partir de los movimientos de la luna, especialmente al verificar el espacio de tiempo entre dos lunas llenas, lo que dio como resultado meses de 29,5 días.

Históricamente se sostiene que las culturas han elaborado sus propios calendarios, como la cultura egipcia que basó sus mediciones temporales en el sol. Esta planteaba que el año solar estaba compuesto 
por trescientos sesenta y cinco días, doce meses de treinta días cada uno y cinco días extras al final. Esta mediación temporal data del 4241 antes de Cristo. Pero, este calendario no era práctico. Cada año al llegar el fin de la primavera aparecía la estrella Sirio, señal estelar que traía el aviso de que el río Nilo inundaría el valle y con este acontecimiento, se iniciaba el ciclo de las cosechas, así como el año nuevo. Para ellos, el calendario empezaba el 15 de junio, momento cuando aparecía por el horizonte la estrella SothisIsis, que ahora se denomina Sirio, era la señal para iniciar los preparativos para la agricultura, porque empezaban las crecidas del río Nilo (Arrillaga, 1993).

Como los trescientos sesenta días no permitían completar el ciclo de aparición de esta estrella en el mismo lugar del cielo en que había aparecido el año anterior, los egipcios agregaron cinco días más al año para ampliarlo a trescientos sesenta y cinco días. Los cinco días adicionales se convirtieron en festivos; pareciera que esta tradición se conserva en la actualidad, al menos, en el mundo occidental. Esto se puede apreciar en la tradición occidental de las vacaciones al final de cada año, cuyo origen se cree que se remonta veinte años atrás. La fiesta de las Saturnales en la antigua Roma: “...era tan apreciada por el pueblo, que de forma no oficial se festejaba a lo largo de siete dias, del 17 al 23 de diciembre. Las autoridades estatales se vieron obligadas incluso a atender a la costumbre popular. A finales del siglo I después de Cristo, las vacaciones judiciales se prolongaron definitivamente a cinco dias..." (Schultz, 1994:15-16).

Pero este calendario estructurado de esta manera, aún era impreciso, porque la Tierra completa su órbita alrededor del Sol en un tiempo un poco menor de trescientos sesenta y cinco días y cuarto. Por lo tanto, cada cuatro años se debe agregar un día, para estar acorde con los movimientos de los cuerpos celestes. Estos cambios necesarios los realizó el Emperador Julio César; por ello, ese nuevo calendario se denomina Juliano, en honor a su nombre.

Por lo expuesto, se puede afirmar que las divisiones de los calendarios tienen como base los movimientos de la Tierra y de los astros. Las sociedades antiguas se basaron en la salida, en la entrada del sol, así como en las fases de la luna. Posteriormente, con el desarrollo científico se planteó que el día y la noche corresponden al movimiento de rotación de la Tierra, que el lapso de tiempo que dura la traslación de la Tierra alrededor del Sol corresponde a un año. 
De acuerdo con los planteamientos anteriores, las sociedades comenzaron a estructurar calendarios o sistemas para medir el tiempo, con el fin de incorporarlos a la vida cotidiana, para buscar soluciones a las distintas necesidades de las sociedades. De ahí que la división del tiempo en días, meses y años son fundamentales para la estructuración social, económica, política y religiosa de la sociedad, porque a partir de estas mediciones se establecen días festivos, sagrados, laborales, comerciales y agrícolas. No es casual entonces, que los romanos también se preocuparan por darle nombre a cada día de la semana; para ello, se basaron tanto en los astros como en los dioses. Así, el lunes lo dedicaron a la diosa Luna, el martes a Marte, el miércoles a Mercurio, el jueves a Júpiter, el viernes a la diosa Venus. El nombre de sábado y domingo proviene más bien de la tradición judeo-cristiana; en ese sentido, sábado corresponde al sabbath o día de descanso de los judíos, domingo proviene de dominicus, día del Señor.

Los griegos, basados en los conocimientos babilónicos, lograron estructurar un calendario alrededor del 300 antes de nuestra era, unos años después de la conquista de Babilonia encabezada por Alejandro Magno, en el año 331 antes de Cristo. Este calendario constaba de doce meses compuestos por veintinueve o treinta días. El año era de 354 días, se le agregaba un nuevo mes cada tercero, sexto y octavo año. Los griegos, en su afán de que un ciclo tuviera un número exacto de años, se fijaron en el período que se daba entre dos lunas nuevas inmediatas. A este ciclo se le denominó Áureo, y aunque no tuvo importancia para la conformación de un calendario práctico, sí lo fue para la programación de fechas festivas religiosas.

Toda esta tradición de medir el tiempo por medio de un calendario con esas características pasó a Roma, y de ahí a toda la civilización occidental.

Muchas civilizaciones y algunos pueblos lograron determinar la fecha en que la duración del día y de la noche son exactamente iguales en todo el planeta, fenómeno que se repite periódicamente aproximadamente cada seis meses, conocido como el equinoccio de primavera, que ocurre cuando el eje de la Tierra es perpendicular en la dirección hacia el Sol, y este se encuentra equidistante de los polos. Se sabe que el equinoccio es el momento del año en que los días tienen igual duración que las noches. Ocurre dos veces al año, alrededor del 21 de marzo y luego, alrededor del 22 de setiembre, porque en esos momentos los polos de la Tierra se encuentran a la misma distancia del sol, razón por la cual 
la luz solar llega en igual cantidad a ambos hemisferios. La palabra equinoccio proviene de dos palabras latinas, a saber: aequus y nox que significan igual, noche.

También las sociedades lograron determinar el día más largo y el más corto del año, es decir, a los que corresponden respectivamente una mayor y menor cantidad de horas de luz, conocidos como solsticios de verano y de invierno. El solsticio es el momento en que el Sol se encuentra más lejos del Ecuador. Por la inclinación del eje terrestre, la luz solar incide muchas horas en uno de los hemisferios y, por el contrario, muy pocas en el otro. El planeta Tierra se encuentra muy cerca del afelio o el perihelio de su órbita, alcanzando estos puntos los días 3 de julio y 3 de enero respectivamente. La posición del Sol vista desde la Tierra, desde su salida, su ubicación a medio día, como la puesta en el horizonte casi no cambia. Este fenómeno se observa durante varios días, antes y después de los solsticios de verano y de invierno (Bialko, 1985).

Lo anterior ocurre por el movimiento de traslación de la Tierra; ésta en su movimiento por la órbita elíptica alrededor del Sol, pasa por puntos especiales que marcan el inicio de las estaciones del año. En el hemisferio boreal, el invierno se inicia el 22 de diciembre, que es el día más corto. Lo mismo ocurre con el inicio del verano el 22 de junio, en el más largo. La primavera $\mathrm{y}$ el otoño entran a partir de sus equinoccios; el 21 de marzo y el 22 ó 23 de setiembre respectivamente. No es de extrañar que, probablemente, las sociedades aprovecharan estas ocasiones para la celebración de fiestas y ritos de carácter religioso o mitológico, o para establecer una tradición a propósito de estos fenómenos.

Desde la Tierra se puede calcular que el Sol está ubicado en la constelación de Piscis, en la fecha en que la duración del día es exactamente igual a la noche, en el equinoccio de primavera. El Sol entró en esta constelación un siglo antes de Cristo, se mantendrá allí hasta el año 2.600. Así, los Peces se convirtieron en la constelación más importante del Zodiaco, término que significa animal en griego. Este acontecimiento no pasó inadvertido para los pueblos de la antigüedad que le daban mucha importancia a la posición de los astros. Se cree que este suceso también tiene relación con el auge místico que estimuló el surgimiento del cristianismo. De hecho, el símbolo religioso de los primeros cristianos no fue la cruz, sino la imagen de un pez (Bialko, 1985).

De lo anterior se desprende la importancia que tiene para un pueblo este acontecimiento astronómico, que lo conduce a establecer 
una tradición de carácter religioso, amalgamando así, como se indicó anteriormente, lo cósmico con lo espiritual, hecho que realizaron otras culturas como la romana en las fiestas Saturnales que festejaban al Dios Saturno, precisamente alrededor de los días más cortos del invierno. Estos festejos constituían un ágape para el pueblo; por eso, eran tan apreciados.

El antiguo calendario romano debido a Rómulo (753-751 antes de Cristo), se estructuró sobre la base de diez meses, con trescientos cuatro días en un año que comenzaba en marzo. Posteriormente Numa Pompilio (714-671 antes de Cristo), agregó dos meses más, enero, febrero, completando, así el año de doce meses y trescientos sesenta días. Sin embargo, en determinado momento del año, las fechas no coincidían con la posición relativa que debía tener la Tierra con respecto del Sol en ese momento, por eso, el Emperador Julio César modificó el calendario para ponerlo de acuerdo con el curso del sol; este cambio se conoce con el nombre de reforma juliana y se realizó en el año 708 de Roma. Se debe recordar que la tradición señala que Roma se fundó en el año 753 antes de nuestra era. El año 708 de Roma equivaldría al 45 antes de Cristo. Roma fue gobernada por Julio César hasta el año 44 antes de Cristo.
De hecho, se agregó un día suplementario cada cuatro años, pero de este modo el año resultaba algo mayor que el verdadero, de suerte que en 1582 había retrocedido el equinoccio de primavera, unos diez días (García, 1976). La diferencia de tiempo de once minutos y catorce segundos requeridos para completar el cuarto día, produjo después de quince siglos una diferencia de alrededor de diez días entre el calendario y la realidad cosmológica.

Ese desfase del equinoccio de Primavera con el Calendario Juliano representaba un serio problema para la iglesia, porque el lugar que le corresponde a la Semana Santa en el calendario, es la semana en la que aparece la primera luna llena después del equinoccio de la primavera en el hemisferio boreal (21 de marzo); de ahí la importancia de la petición que le hiciera la Iglesia Católica a Copérnico, puesto que el verdadero equinoccio no coincidía con lo establecido en los calendarios. Esta situación era delicada, porque se corría el riesgo de celebrar las liturgias de Semana Santa en una fecha equivocada, desfasando en el tiempo la relación cósmica que tenían la pasión y la muerte de Cristo.

Se debe tener presente que en los calendarios modernos, las fases de la luna no son importantes para determinar el número de días de un mes; la duración de los meses es 
aproximadamente una duodécima parte de un año solar; es decir, oscila entre veintiocho y treinta y un días. Los ajustes se hacen para coincidir con la división en doce meses del año solar; el hecho de que coincida con los doce meses que ya otras culturas tenían, es porque la conformación del calendario ha sido un proceso de miles de años, lo que imposibilita cambiarlo de manera total, por lo menos en este aspecto.

En 1514, el Papa pidió al matemático polaco Nicolás Copérnico que reformara el calendario. Copérnico estuvo de acuerdo, pero le señaló que la ubicación de los cuerpos celestes y sus movimientos debía resolverse. Esto lo hizo Copérnico en 1543, el año de su muerte; lo publicó en el texto que lleva por nombre "Sobre la revolución de las esferas celestes", libro en el que se cuestiona la visión cosmológica aristotélica que había predominado durante los últimos dos mil años.

No obstante lo anterior, es hasta el año 1582 cuando el Papa Gregorio XIII ordenó las reformas al calendario basado en las tesis de Copérnico. Como resultado, apareció el calendario vigente hasta nuestros días, denominado Gregoriano, que toma como punto de partida el nacimiento de Jesucristo.

A pesar de las reformas astronómicas hechas por Copérnico, la historia indica que mil años antes los mayas, basados en sus tesis astronómicas ya habían elaborado un calendario aún más preciso que el Gregoriano que es el vigente actualmente (C.f. Aveni, 2005, 226).

Efectivamente, las culturas azteca y maya también confeccionaron sus propios calendarios, cuyo proceso de observación de los astros difiere en parte del aporte europeo-asiático.

\section{Conclusión}

El ser humano, a lo largo de la historia ha creado técnicas para solventar sus necesidades, lo que permitió incursionar en diversas actividades y formas de asociación para el desarrollo de las labores. Gracias a la observación del cosmos y de algunos fenómenos naturales fue capaz de elaborar calendarios, que han sido de gran ayuda en el desarrollo económico de las sociedades, así como en la conformación ideológica de éstas. La observación de la naturaleza y el cuestionamiento sobre algunos hechos derivó en una producción mitológica que sustentó el imaginario colectivo, motivó a la Iglesia Católica a decretar fechas específicas para las festividades religiosas, como la navidad, la cuaresma, la pascua y las celebraciones en honor a los santos. 


\section{Bibliografía}

Aveni, Anthony (2005). Observadores del cielo en el México Antiguo. México. Fondo de Cultura Económica.

Abadiano, Dionisio (1989). Estudios arqueológicos y jeroglíficos del calendario o gran libro astronómico, histórico y cronológico de los antiguos indios. México. Secretaría de Fomento de México.

Academia de Ciencias de la U.R.S.S, Instituto de Economía (1957). Manual de Economía Política. México. Editorial Grijalbo.

Arrillaga, Rafael (1993). Introducción a los problemas de la Historia. Madrid. Alianza Editorial, S.A.

Berenzon Gorn, Boris (1999). Historia es inconsciente. México. Editorial Colegio de San Luis de Potosí.

Bernal, John (1979). La ciencia en la Historia. (Vol1). 4ta edición. México. Editorial Nueva Imagen.

Bialko, A. (1985). Nuestro planeta la Tierra. Moscú. Editorial Mir.

Bravo, Gonzalo (2008). Historia del mundo antiguo. Madrid. Editorial Alianza.

De la Paz, Marco (1991). Calendario Maya, el camino infinito del tiempo. Guatemala. Ediciones Gran Jaguar.

Domené, Domingo (2010). El origen de las fiestas. La cristianización del calendario. Madrid. Editorial Laberinto.

Díaz Infante, Fernando (1987). La estela de los soles o calendario azteca. México. Panorama Editorial. México.

Eliade, Mircea (1973). Aspectos del mito. Madrid. Ediciones Guadarrama, S.A.
Fraile, G. (1966). Historia de la Filosofía. Madrid.

Girard, Rafael (1948). El calendario MayaMexica. México. Editorial Stylo.

Llul, Josep (2005). La astronomía en el antiguo Egipto. Valencia. Editorial PUV. Universidad de Valencia.

Martín, Thomas (2000). Grecia Antigua. U.S.A. Yale University Press.

McNall Burns, Edgard (1970). Civilizaciones de Occidente. Su Historia y su cultura. Buenos Aires, Argentina. Ediciones Peuser.

Mason, Stephen (1984). Historia de las Ciencias. La Ciencia Antigua, la Ciencia en Oriente y en la Europa Medieval. Madrid. Editorial Alianza.

Ribeiro, Darcy (1976). El proceso civilizatorio. México. Editorial Extemporáneos, S.A.

Ricoeur, Paul (1987). Tiempo y narración. La configuración del tiempo histórico. Madrid. Editorial Cristiandad.

Shulz, Regine (2007). Egipto el mundo de los faraones. Colonia. Editorial Koneman.

Strudwick, Helen (2007). Antiguo Egipto. Madrid. Editorial Edimat.

Kuhn, Thomas S. (1996). La revolución copernicana. Barcelona. Editorial Ariel, S.A.

Shultz, Uwe (1994). La fiesta de las Saturnales a Woodstock. Madrid. Editorial Alianza.

Turner, Ralph (1974). Las grandes culturas de la humanidad. Las ciudades antiguas. México. Fondo de Cultura Económica. 
Vera, Luis Angel (2010). Breve historia de las ciudades del mundo antiguo. Madrid. Editorial Nowtilus.

Weber, Max (1971). Economía y sociedad. (Tomos I y II). La Habana, Cuba. Editorial Ciencias Sociales.
Wolf, Eric (1967). Pueblos y culturas de Mesoamérica. México. Ediciones Era.

Woolky, Leonar, Ur (1985). La ciudad de los caldeos. México. Fondo de Cultura Económica. 